\title{
Cholera Prophylaxis is Plumbing and Prosperity
}

THE sad condition of Bengal will remain as a sombre reproach to developed nations for many years to come. That circumstances could have arisen in which several million people should feel it prudent to pack up their belongings and move to an unfamiliar place is an echo of the way in which migration was forced on mediaeval people by events over which they had no control. It is, of course, insufferable that similar migrations should be forced on all too innocent populations at times when individuals in developed nations are confident that, even if they do not own a second motor car or a colour television set, they are at least their own masters. Since the Second World War, there has been no marked decrease in the prevalence of refugees and in that spirit practical men will no doubt be concerned not so much with making the columns of refugees go away as with working out ways of accommodating them more easily. The occurrence of cholera, a threat ever since the army of Pakistan moved against the recessionists, is one of many symptoms to be treated.

By now, natural as well as artificial disasters are frequent enough and damaging enough for the threat of disease of some kind to be recurrent. Earthquakes in Turkey or the Andes constantly provoke fears of cholera epidemics and so too do natural catastrophes such as the typhoon that killed a million people in the Bay of Bengal less than a year ago. Most often, the threat turns out to be ill-founded. Disaster strikes but nothing follows. This no doubt is why the threat of cholera among the refugees in East Bengal seems to have lain dormant for the best part of a month. After all, the time for flying vaccine and saline solutions to Calcutta was the beginning of May, not the beginning of June. To be sure, it would be unreasonable to expect that private companies would make speculative arrangements of this kind-they have no particular reason to tie up resources in ways like that and indeed they might be considered ghouls for seeking, as it might seem, to turn disaster to their own advantage. So how are steps to be taken for avoiding sudden shortages of medical supplies like those which have become apparent in the past few days? Is this not a situation in which some international organization should act as a banker, keeping a lien on available stocks, wherever manufactured, against emergencies which might arise, and being prepared to release these to the ordinary commercial markets in other circumstances ? This, in practice, is the way in which the orderly distribution of raw materials such as tin is administered. The advantage of such a system, and the goal to which both the manufacturers of vaccines and other medical supplies as well as the international aid-giving authorities should work, is the benefit that comes from making a diversity of supplies available to a common pool. And is it not necessary that arrange- ments like these should be administered not by national governments but by the specialized agencies of the United Nations ? Where cholera is concerned, the orders of magnitude are, after all, easy enough to predict. There is probably a continuing need for some millions of doses of vaccine and for enough saline solution to treat 100,000 patients or thereabouts. Keeping such a stockpile fresh ought not to be an insuperable task. Similar precautions should, of course, be taken to guard against the threat of diseases of other kinds, from plague to yellow fever.

As it happens, exactly similar arrangements are necessary if the United Nations is to be in a position to deal with other kinds of international disasters, from typhoons to earthquakes. The experience of the past few years has shown quite clearly that there is a need for an internationally accessible pool of helicopters and for ways of moving communications equipment into regions where existing arrangements are disrupted by emergencies. Here again, the United Nations or one of its agencies should be given a lien on facilities rather than outright ownership of them. The chances are that thoroughly commercial organizations would be prepared to come to an accommodation of some kind with the international agencies. The cost need not be excessive, but the unhappy lessons of the recent past argue for speedy attention to the problem.

In the long run, however, no amount of vaccination will be sufficient safeguard against cholera. The longterm defence must be better plumbing, not simple vaccination. It is also relevant that the incidence of cholera, like that of many other diseases of the developing countries, is closely dependent on nutrition. People who are well nourished are much less susceptible. It follows that the best defence against cholera is nothing less than the old-fashioned recipes which the aid-givers have been advocating for decades-the general improvement of health and welfare. It goes without saying, of course, that by comparison with the cost of the vaccines which have been rushed to Calcutta this week, this is enormously expensive. To provide a developing population of a million people with decent housing and plumbing would no doubt cost much more than the annual product of the nations to which they belong, but it would also require changes in the balance between city and rural life. In the long run, it is of course unthinkable that such facilities could be financed from sources other than the productivity of the people concerned, which in turn implies that the ultimate defence against cholera and diseases like it is not even plumbing but prosperity. It may be too much to hope that mere economic advancement will remove the underlying causes of the unhappy migration of the past few weeks but there is at least a chance that it could take the edge of some of the anxieties which the migration has caused. 